\title{
Growth of Oxide Laser Crystals by Czochralski Method
}

\author{
E.V. Zharikov*, D.A. Lis, K.A. Subbotin, V.B. Dudnikova and O.N. Zaitseva \\ A.M. Prokhorov General Physics Institute of Russian Academy of Sciences \\ Vavilova St. 38, 119991 Moscow, Russia
}

\begin{abstract}
The growth of series of actual laser crystals belonging to different structural types by the Czochralski method is presented. The primary attention is given to single crystalline compounds and their solid solutions with garnet structure (scandium-containing rare-earth garnets with general formula $\left.\{\mathrm{LnSc}\}_{3}[\mathrm{ScMe}]_{2} \mathrm{Me}_{3} \mathrm{O}_{12}, \mathrm{Me}=\mathrm{Al}, \mathrm{Ga}\right)$ as well as with olivine (forsterite $\mathrm{Mg}_{2} \mathrm{SiO}_{4}$ ) and scheelite structure (double tungstates and molybdates with formula $\mathrm{NaLn}\left(\mathrm{TO}_{4}\right)_{2}$, where $\mathrm{T}=\mathrm{Mo}$ or $\left.\mathrm{W}\right)$. The broad bands of luminescence and absorption produced by activator ions in these laser hosts that appear either as a result of structural disorder (garnets, scheelites) or due to the doping by transition metal ions (chromium in forsterite) join together these representatives of different structural classes and determine their application in photonics. The paper considers the problems of growing of large crystals with uniform distribution of components and dopants, determination of congruently melting composition, especially in compounds with complex isomorphism. The mutual influence of components and dopants, redistribution of ions along crystallographically non-equivalent sites in the structure, alteration of valency of transition metal ions accompanied with the change of their segregation coefficients under variation of redox conditions is discussed.
\end{abstract}

DOI: 10.12693/APhysPolA.124.274

PACS: $81.10 . \mathrm{Fq}, 42.70 . \mathrm{Hj}$

\section{Introduction}

Proposed by Jan Czochralski method of crystal pulling from melt in 1918 [1], becomes now one of the most widely used methods for growth of dielectric and semiconductor crystals. Today, after 95 years Czochralski technique continues to progress and get replenished; the today's status of the method is presented in Ref. [2] and last advances and developments are given in Ref. [3].

The first reported oxide material $\left(\mathrm{CaWO}_{4}\right)$ was grown using the Czochralski technique in 1960 [4]. Since then the many tens of other oxide laser crystals appeared, and majority of them were growed by Czochralski method. Extensive collection of papers devoted to laser crystal growth was published recently in Ref. [5].

The present paper considers some aspects of the Czochralski growth technology of a number of actual laser crystals belonging to different structural types. The primary attention will be given to single crystalline compounds and solid solutions with structures of garnet $\left(\mathrm{Ln}_{3} \mathrm{Me}_{5} \mathrm{O}_{12}\right.$ and $\{\mathrm{LnSc}\}_{3}\left[\mathrm{ScMe}_{2} \mathrm{Me}_{3} \mathrm{O}_{12}, \mathrm{Me}=\right.$ $\mathrm{Al}$, Ga), olivine (forsterite $\mathrm{Mg}_{2} \mathrm{SiO}_{4}$ ) and scheelite (double tungstates and molybdates with general formula $\operatorname{NaLn}\left(\mathrm{TO}_{4}\right)_{2}$, where $\mathrm{Ln}=\mathrm{Y}, \mathrm{Bi}, \mathrm{La}, \mathrm{Gd}, \mathrm{Lu}$; $\mathrm{T}=$ Mo or $\mathrm{W}$ ).

Crystals belonging to all above mentioned structural types are essentially different in physico-chemical properties that is necessary to take into account at development of technology of their growing $[6,7]$. They are also different in the structure, cations arrangement as well as in symmetry and coordination of crystallographic sites which offers the possibility to incorporate quite various dopants [8].

*corresponding author; e-mail: zharikov@lsk.gpi.ru
However, one important feature pools them together. There is a broadband absorption and fluorescence. Use of laser materials with broadband fluorescence gives the possibility to create the tunable solid-state lasers and lasers emitting ultra-short pulses in mode-locking regime. On the other hand, the broad absorption band results in essential enhancement of overall efficiency of diode-pumped solid state lasers, since the power consumption of diode coolers for temperature control of laser diode wavelength now is not required, because the temperature-induced fluctuations of the radiation wavelength of the pumping diode become noncritical.

The materials under study demonstrate the broad absorption and fluorescence due to the different reasons. In case of doping by transition metal ions (in particular, chromium-doped forsterite and garnets) the broad and intensive absorption and fluorescence bands arise from vibronic transitions of particular ion in the laser medium. Another reason is in case of garnets and scheelites doped by rare-earth ions. This is the structural disorder originating from the isomorphic substitution. The large isomorphic capacity and possibility of incorporation of high concentrations of neodymium and other rare-earth ions without substantial quenching are the attractive features of both of these structures. Statistical (or quasi-statistical) distribution of ions of different type among identical crystallographic sites produces a partial structural disorder in such materials that leads to inhomogeneous broadening of spectral lines of rare-earth activators. Wide ranges of homogeneity in garnets and scheelites easily allow to vary the structural disorder and create the desirable disordered crystalline media. Growth of crystals of solid solutions give the additional possibilities in this respect.

Growth of crystals by the Czochralski method offered the possibility to vary in wide range the conditions of growth (oxidizing-reducing character of ambient atmo- 
sphere, temperature gradients, stirring in melt, etc.). The paper considers the problems of growing of large crystals, with uniform distribution of components and dopants along and across the crystal. There are discussed such aspects of problem of composition constancy as determination of congruently melting composition, mutual influence of components and dopants, redistribution of ions along crystallographically non-equivalent positions in the structure etc. Influence of above-mentioned factors on spectral-luminescent characteristics and defect formation in crystals are discussed.

Further improvement of crystal quality and intensification of growth kinetics brings the use in growth technology the phenomenon of vibrational convection $[9,10]$ arising in the liquid under applied to the growth system the axial low-frequency vibrations of small amplitude. The controlled axial vibrations in the growth system efficiently affect distribution of the temperature and composition in liquid near front of crystallization, as well as on the shape of the interface. They can also drastically affect surface tension driven flows (the Marangoni convection) and smooth or completely eliminate temperature fluctuations at the interface resulting in essential reduction of intensity of growth striation leading to obtaining the crystals of high perfection.

\section{Rare-earth scandium garnets}

The first publications devoted to rare-earth scandium garnets (RESG) appeared rather long ago, however, these laser crystals remain actual matter today due to their remarkable spectral-luminescent and laser properties. Representatives of RESG are included in a short list of laser crystals used in practice nowadays. Commercial production of RESG single crystals continues today (see, for instance, [11]), novel efficient diode-pumped lasers emitting on practically important wavelengths [12, 13], as well as high-average power femtosecond lasers are developing on their base $[14,15]$; more and more widely RESG solid state lasers are used in medicine [16, 17]. Recently a new interest got scandium garnets in connection with development of transparent ceramics technology and creation of efficient ceramic lasers [18, 19] and white-emitting diodes, scintillators $[20,21]$ using the different RESG compounds.

Multicomponent systems possessing several non-equivalent crystallographic sites often demonstrate rather complicated isomorphism. The distinctive feature of RESG consists in complex scandium isomorphism in these compounds. The regularities of isomorphic substitution of scandium in RESG are connected with the fact that scandium oxide forms wide fields of solid solutions with both aluminum and gallium oxides, as well as with rare-earth oxides. RESG are complex non-stoichiometric compounds in which two of three sublattices are jointly occupied by cations of different kinds. The real scheme of the substitution can be represented by the structural formula suggested in [22, 23]: $\left\{\mathrm{Ln}_{3-x} \mathrm{Sc}_{x}\right\}\left[\mathrm{Sc}_{2-y} \mathrm{Me}_{y}\right]$ $\left(\mathrm{Me}_{3}\right) \mathrm{O}_{12}$ where $\mathrm{Ln}$ denotes a rare-earth element and Me gallium or aluminum; the braces indicate dodecahedral sites, the brackets octahedral sites and the parentheses tetrahedral sites.

Redistribution of $\mathrm{Sc}^{3+}$ on sublattices of garnet structure depends on initial garnet composition, in particular on $\mathrm{Sc}^{3+}$ concentration, as well as on temperature. The alteration of initial content of scandium essentially changes its distribution on crystallographic nonequivalent sites of the lattice. At small concentrations scandium ions occupy only octahedral sites in RESG. The increase of initial $\mathrm{Sc}^{3+}$ content leads to the entry of scandium also into dodecahedral sites that results in the break of straightforward dependence of lattice parameter on crystal composition [24]. The replacement by scandium a part of the rare-earth ions in the dodecahedral sites leads to maintaining in this way a necessary average size proportion of coordination polyhedra in the structure.

The increase of temperature leading to general extension of the lattice and increase of effective sizes of coordination polyhedra causes the partial transition of $\mathrm{Sc}^{3+}$ ions from dodecahedral sites to octahedral ones, the so-called $\mathrm{C} \rightarrow \mathrm{A}$ transition [22]. Such cation redistribution is thermally reversible and this process becomes easier in the presence of oxygen and cation vacancies.

The dependence of positional redistribution of scandium on the composition is demonstrated by congruently melting compositions of RESG, which are presented in Table I. It is seen that the congruently melting compositions of RESG, indicating the structural disorder, are quite different from stoichiometric ones that is unlike to YAG as well as to GGG. The data demonstrate that with the change of initial composition of garnet both the total content of $\mathrm{Sc}^{3+}$ in RESG, and the grade of filling of octahedral sites by scandium as well as quantity of its entry in dodecahedral sites of garnet structure change. The type of cations occupying the tetrahedral and dodecahedral sublattices renders the substantial influence on these processes.

It should be stressed that the congruently melting composition which was determined for nominally pure multicomponent compound cannot always be used for growth of uniform crystals containing the dopant. Due to influence of dopants on composition it must be shifted to so-called "optimum composition" to be able to grow crystal with only slightly changed concentrations of components (and dopants) along the boule. In particular, the presence of $\mathrm{Cr}^{3+}$ ions in the GSGG charge even in such small concentration as 0.63 at.\% causes the significant changes: increase of Sc-content for about $20 \%$ in addition with incorporation of Sc into dodecahedra (Gd-sites) [7].

For preparation of RESG solid solutions the original procedure was used. The individual ternary garnets (GSGG, YSGG and GSAG) with compositions corresponding to congruently melting composition (CMC) points were used as components. We found that the character of melting of obtained solid solutions appeared to be close to congruent in a full range of mixtures (see Fig. 1). Distribution coefficients of the main components as well as chromium and rare-earth dopants were close 
to unity. The thermal conductivity of scandium garnet mixtures remains at the same level as for initial components [25]. By selection on RESG mixture composition it is possible to adjust the spectroscopic parameters of active medium. For instance, in case of $\mathrm{Nd}^{3+}$ it is easy to get variable lasing wavelength of mixtured RESG in the range from 10585 to $10612 \AA$ [26].

\section{TABLE I}

Congruently melting compositions (CMC), scandium content in octahedral sites and distribution coefficients of $\mathrm{Cr}^{3+}$ and $\mathrm{Nd}^{3+}$ ions in garnets.

\begin{tabular}{c|c|c|c|c}
\hline \hline Garnet & CMC & $\mathrm{Sc}_{\text {oct }}[\%]$ & $K_{\mathrm{Cr}}$ & $K_{\mathrm{Nd}}$ \\
\hline GSGG & $\left\{\mathrm{Gd}_{2.95} \mathrm{Sc}_{0.05}\right\}\left[\mathrm{Sc}_{1.85} \mathrm{Ga}_{0.15}\right]\left(\mathrm{Ga}_{3}\right) \mathrm{O}_{12}$ & 93 & 1.0 & 0.7 \\
GSAG & $\left\{\mathrm{Gd}_{2.88} \mathrm{Sc}_{0.12}\right\}\left[\mathrm{Sc}_{1.77} \mathrm{Al}_{0.23}\right]\left(\mathrm{Al}_{3}\right) \mathrm{O}_{12}$ & 88 & 1.1 & 0.6 \\
YSGG & $\left\{\mathrm{Y}_{2.93} \mathrm{Sc}_{0.07}\right\}\left[\mathrm{Sc}_{1.36} \mathrm{Ga}_{0.64}\right]\left(\mathrm{Ga}_{3}\right) \mathrm{O}_{12}$ & 68 & 1.4 & 0.6 \\
YSAG & not found & var & $1.6-2.1^{*}$ & $0.2-0.3^{*}$ \\
YAG & $\left\{\mathrm{Y}_{3}\right\}\left[\mathrm{Y}_{0.02} \mathrm{Al}_{1.98}\right]\left(\mathrm{Al}_{3}\right) \mathrm{O}_{12}$ & - & 2.4 & 0.18 \\
GGG & $\left\{\mathrm{Gd}_{3}\right\}\left[\mathrm{Gd}_{0.05} \mathrm{Ga}_{1.95}\right]\left(\mathrm{Ga}_{3}\right) \mathrm{O}_{12}$ & - & 3.3 & 0.63 \\
\hline
\end{tabular}

* depending on the composition

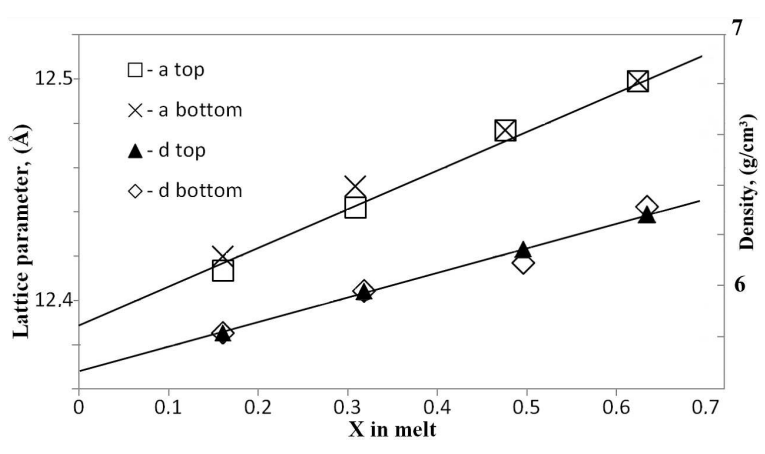

Fig. 1. Lattice parameters $(a)$ and densities $(d)$ of $\mathrm{GSGG}_{x} \mathrm{GSAG}_{1-x}$ mixed single crystals depending on composition of the melt. $a$ - and $d$-lines connect the corresponding values of GSAG and GSGG congruent melting compositions.

RESG crystals were grown by the Czochralski technique with (111)- and (100)-oriented seed crystals from iridium cruicibles of 40 and $80 \mathrm{~mm}$ diameter. Initial oxides of $5 \mathrm{~N}$ purity preliminary calcined and taken in proper proportion are mixed and pressed in tablets of crucible size. Preliminary synthesis of the charge is performed before filling of the crucible which is a necessary procedure in case of scandium-gallium garnets in order to bind aggressive $\mathrm{Ga}_{2} \mathrm{O}_{3}$ into complex compounds (garnet, perovskite). Growth conditions were characterized by an ambient atmosphere of $\mathrm{N}_{2}+0.5-2$ vol.\% $\mathrm{O}_{2}$ for Ga-content crystals. Slightly oxidized atmosphere allows minimizing gallium oxide evaporation and iridium losses. Nitrogen atmosphere containing about 0.1 vol.\% of $\mathrm{O}_{2}$ was used for growing of the aluminum garnets. Rotation rates were in the range of $10-30 \mathrm{rpm}$, and pulling rates were $1.5-3 \mathrm{~mm} / \mathrm{h}$ depending on the composition and dopant concentrations. Knowledge of true congruently melting compositions together with large distribution coefficients of dopants $\left(\mathrm{Ln}^{3+}\right.$ and $\left.\mathrm{Cr}^{3+}\right)$, which are close to the unity (see Table I) allow to grow RESG with rather high pulling rates and give a real possibility to grow doped crystals with flat interface. The large laser crystals, up to $40 \mathrm{~mm}$ diameter, $120 \mathrm{~mm}$ length, and more than $1 \mathrm{~kg}$ in weight, were grown with a flat solid-liquid interface. The crystal-diameter-to-crucible-diameter ratio was up to $0.4-0.6$, and the crystallized melt fraction up to $60 \%$.

The scandium isomorphism in RESG considerably influences the crystal growth, since scandium garnets possess wide range of homogeneity at rather flat liquidus. In this connection, the temperature oscillations at the interface can cause substantial variations of the crystallized composition that appear as formation of growth striations with changing of the content of both the main components and the dopants. The growth striations in their turn lead to the undesirable local variations of refraction index. At the laser operation the laser beam quality deteriorates because of scattering on these inhomogeneities.

Due to smaller thermal conductivity of the solid and smaller viscosity of the melt ScGa-garnets can much more easily be grown with flat interface in comparison with ScAl-garnets [25, 27]. At the same time, in more viscous melts containing aluminium oxide owing to disturbance due to crystal rotation the temperature oscillations easily occur and, as a result, more pronounced local variations of the composition take place.

The insertion of chromium into RESG increases the absorption capability of the medium by an order of magnitude greater or more in comparison with ordinary laser materials due to formation of strong absorption bands of $\mathrm{Cr}^{3+}$. Usually, the average absorption coefficient in the visible and near IR-region of spectrum for these crystals lies in the region from 3 to $12 \mathrm{~cm}^{-1}$ depending on chromium concentration. For comparison the same absorption coefficient for Nd:YAG is equal to about $0.2 \mathrm{~cm}^{-1}$. Such substantial rise of the absorption capacity of the medium considerably decreases the heat removal by radiation from the interface during the growth. 
This leads to the decrease of temperature gradients in the melt near the interface that in its turn affects the stability of the crystal growth and causes difficulties in the maintenance of the constant diameter of the crystal.

The additional absorption becomes even stronger and instabilities during the growth correspondingly increase, when the changing of charge state of a part of $\mathrm{Cr}^{3+}$ ions takes place and tetrahedrally coordinated $\mathrm{Cr}^{4+}$ ions are created due to the presence of two-valent impurities like $\mathrm{Ca}^{2+}, \mathrm{Mg}^{2+}$, etc. in the melt. In this connection for the growing of high-quality crystals the automation of growth process is the necessary element of technology.

Insertion of optically inactive ions can cause the change of charge state of activator ion as it is in chromium-content garnets co-doped with $\mathrm{Me}^{2+}$ ions. Study of interaction of calcium and chromium in gadoliniumscandium-aluminum garnet (GSAG) show [28] that effective distribution coefficient of $\mathrm{Cr}^{4+}\left\{\mathrm{K}\left(\mathrm{Cr}^{4+}\right)\right\}$ considerably depends on $\mathrm{Ca} / \mathrm{Cr}$ ratio in the melt. Initial calcium concentration had been varied from $6 \times 10^{17} \mathrm{~cm}^{-3}$ to $1 \times 10^{20} \mathrm{~cm}^{-3}$ and chromium concentration - from $5 \times 10^{19} \mathrm{~cm}^{-3}$ to $3 \times 10^{20} \mathrm{~cm}^{-3}$. At low $\mathrm{Ca}^{2+}$ initial concentration $(\mathrm{Ca} / \mathrm{Cr}=0.05)$ distribution coefficient of $\mathrm{Cr}^{4+}$ determined from absorption spectra was very low (0.08) and $\mathrm{K}\left(\mathrm{Cr}^{4+}\right)$ increased along with enhancement of $\mathrm{Ca}$ amount until about 0.3 at $\mathrm{Ca} / \mathrm{Cr}=2.0$. At the same time distribution coefficient of total chromium which was measured by microprobe analysis reduced from 1.5 to 1.3 . The influence of calcium content and $\mathrm{Ca} / \mathrm{Cr}$ ratio on chromium lifetime in GSAG crystals have been found. When ratio $\mathrm{Ca} / \mathrm{Cr}$ increases, the fluorescence decay time of $\mathrm{Cr}^{4+}$ (as well as $\mathrm{Cr}^{3+}$ ) considerably reduces. In fact, at $\mathrm{Ca} / \mathrm{Cr}=2.0$ the $\mathrm{Cr}^{4+}$ lifetime in $\mathrm{GSAG}$ is equal to $2.6 \mu \mathrm{s}$ that is twice as low in comparison with crystal which had concentration ratio $\mathrm{Ca} / \mathrm{Cr}=0.05$.

\section{Forsterite}

Forsterite, magnesium orthosilicate $\mathrm{Mg}_{2} \mathrm{SiO}_{4}$, has orthorhombic structure (space group Pbnm) and belongs to the group of olivine, which is one of the most important rock-forming mineral. Forsterite has been widely used in refractory engineering, and in the chromium-doped form it is the known laser material. Great interest in forsterite doped with chromium arose when the tunable lasing in the near IR range was obtained on tetravalent chromium ions [29]. A new laser material has been synthesized in the form of forsterite crystals with active centers, i.e., associates of chromium and lithium ions, on which the tunable laser generation has been achieved in a new spectral

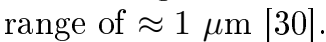

It is known that chromium can occur in synthetic forsterite crystals in different valence states, such as $\mathrm{Cr}^{2+}, \mathrm{Cr}^{3+}$, and $\mathrm{Cr}^{4+}$. Divalent and trivalent chromium ions substitute for magnesium ions and can be located in two structurally nonequivalent octahedral positions M1 and M2. Experimental observations have revealed that trivalent chromium ions can exist not only in the isolated form but also as associates with magnesium vacancies $[31,32]$. Tetravalent chromium ions substitute for silicon ions in tetrahedral sites. The ratio between different chromium species can be altered depending on the growth conditions. However, the content of chromium ions in forsterite is usually not very high: it amounts to several hundredths of a weight percent for tetravalent chromium and does not exceed several tens of a weight percent for trivalent chromium.

The important task to be solved for forsterite crystal growth is increase of concentration of the laser centers and purposeful change of ratio between different chromium species. In order to increase the efficiency of $\mathrm{Cr}^{4+}$ forsterite lasers, it is necessary to minimize the concentration of other ions, because the absorption and luminescence bands for mixed-valence chromium ions are partially overlapped with each other, which results in a decrease in the laser efficiency.

Growth of forsterite laser crystals by the Czochralski method and related problems we studied in a number of papers [33-39]. The forsterite single crystals were grown by the Czochralski method from iridium crucibles with RF heating at inert or slightly oxidizing atmosphere $\left(\mathrm{N}_{2} /\right.$ Ar inert gas with $1 \div 2 \mathrm{vol} . \%$ of $\left.\mathrm{O}_{2}\right)$. Pulling/rotation rates were usually $2-4 \mathrm{~mm} / \mathrm{h}$, and $10-30 \mathrm{rpm}$, respectively. A charge of stoichiometric composition was prepared from $\mathrm{MgO}$ and $\mathrm{SiO}_{2}$ of extra-pure grade. The oxides had been preliminarily calcined at $700{ }^{\circ} \mathrm{C}$ during $8 \mathrm{~h}$, mixed, pressed into the tablets and fired again at $1050{ }^{\circ} \mathrm{C}$ during $30 \mathrm{~h}$. The required amount of $\mathrm{Cr}_{2} \mathrm{O}_{3}$ and other dopants were added into the crucible directly before the growth process. All the crystals were grown on seeds oriented along the $a$ axis (Pbnm notation). In order to avoid cracks formation, after a growth-run the crystal should be cooled down to room temperature with the rate $50-100^{\circ} \mathrm{C} / \mathrm{h}$ depending on the size of grown boule.

Forsterite has strictly stoichiometric composition with very narrow $\mathrm{MgO}-\mathrm{SiO}_{2}$ homogeneity field. Thus, thorough control of $\mathrm{MgO}: \mathrm{SiO}_{2}$ ratio in the charge is required [40]. The composition of crystals grown from the charge of stoichiometric composition and with an excess of $\mathrm{MgO}$ (up to $2 \mathrm{wt} \%$ ) or $\mathrm{SiO}_{2}$ (up to $2.0 \mathrm{wt} \%$ ) was investigated using electron probe microanalysis. However, we did not reveal an excess of magnesium or silicon in single-phase forsterite crystals; this excess was observed only in the form of second phases that were precipitated in the case of a strong deviation of the composition of the initial charge from the stoichiometric composition.

\subsection{The dependence of $K_{\mathrm{Cr}}$ on chromium concentration}

The series of crystals with different content of chromium in the melt (from 0.01 to $1.4 \mathrm{wt} \%$ ) was grown with fixed $P_{\mathrm{O}_{2}}$ in the growth atmosphere $\approx 2.2 \pm 0.1 \mathrm{kPa}$ for study of influence of doping level on distribution coefficient of chromium $\left(K_{\mathrm{Cr}}\right)$.

The results of experimental determination of $K_{\mathrm{Cr}}$ dependence on $C_{\mathrm{Lo}}$ are shown in Fig. 2a. The distribution coefficient was obtained by extrapolation of the plot $C_{\mathrm{S}} / C_{\mathrm{Lo}}$ versus $g$ to the starting crystallization point $(g=0)$. For a better representation of the behavior of chromium in the low concentration range, the chromium 
content in the melt is given on a logarithmic scale. It can be seen that, in the range of the lowest concentrations of chromium, it is most effectively incorporated into the crystal. The observed phenomenon is explained by the interaction of impurities with intrinsic defects of the crystal, which is called as the microimpurity trapping effect [41]. Figure 2a indicates that the $K_{\mathrm{Cr}}$ can be considered as fixed only for $C_{\mathrm{Lo}} \leq 0.1-0.2 \mathrm{wt} \%$. With a further increase in the impurity content in the melt, the value of $K_{\mathrm{Cr}}$ decreases. The $K_{\mathrm{Cr}}$ decreases more than by factor of 3 in the investigated range of concentration.

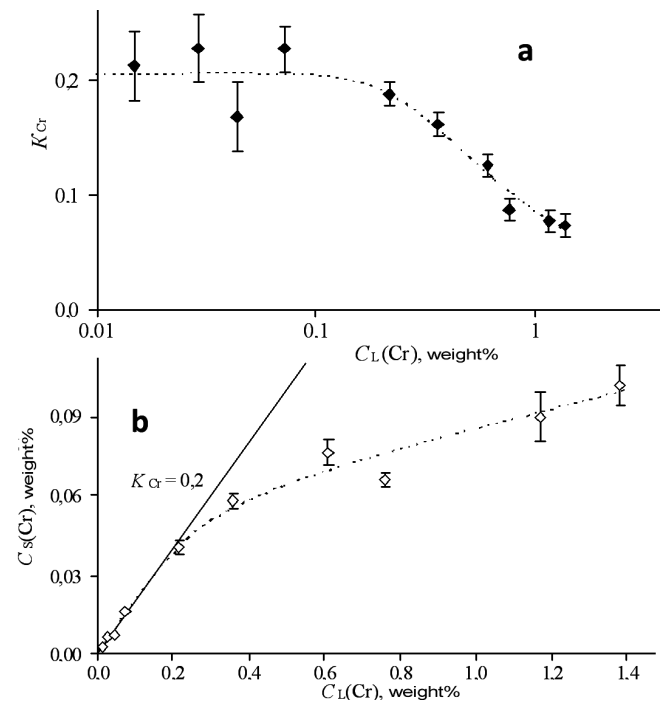

Fig. 2. Dependences of chromium distribution coefficient of forsterite (a) and the content of chromium in the crystal on its concentration in the melt (b).

Figure $2 \mathrm{~b}$ shows the changes observed in the chromium content in the crystal $C_{\mathrm{S}}(\mathrm{Cr})$ with variation in the chromium concentration in the melt. The solid line in Fig. 2 b represents the dependence of $C_{\mathrm{S}}(\mathrm{Cr})$ on $C_{\mathrm{Lo}}(\mathrm{Cr})$, which should be expected at a constant coefficient of chromium distribution between the crystal and the melt of forsterite $\left(K_{\mathrm{Cr}}=0.21\right)$. The real correlation between $C_{\mathrm{S}}(\mathrm{Cr})$ and $C_{\mathrm{Lo}}(\mathrm{Cr})$ (which determine coefficient of $\mathrm{Cr}$ distribution between crystal and melt) significantly deviates from the linear dependence. Chromium concentration in crystal is significantly lower than the value expected at the constant $K_{\mathrm{Cr}}$, and the difference rises with increasing $C_{\mathrm{Lo}}(\mathrm{Cr})$. As is seen from Fig. $2 \mathrm{~b}$ the maximum solubility of chromium in the grown crystals is $0.1 \mathrm{wt} \%$. This crystal was grown from the melt with chromium concentration $1.4 \mathrm{wt} \%$.

The changes in the concentrations of chromium species with different valences [38] are similar in character to the dependences of the concentration of total chromium content in the crystal on its content in the melt (Fig. 2b).

\subsection{The dependences of $K_{\mathrm{Cr}}$ on $\mathrm{P}_{\mathrm{O}_{2}}$}

The total concentration of chromium in forsterite crystals is low, does not exceed $0.1 \mathrm{wt} \%$, and, as a rule, it is equal to several hundredths of a weight percent [38]. The content of $\mathrm{Cr}^{4+}$ ions which are active laser centers is considerably lower and, most likely, does not exceed several thousandths of a weight percent. In this respect, the search for ways of increasing the concentration of active centers is an important problem.

In a number of works [42-44], in order to provide maximum amounts of $\mathrm{Cr}^{4+}$ ions, crystals were grown at maximum oxygen content in the growth atmosphere up to the use of pure oxygen at a pressure as high as 4 atm. However, the results obtained were evaluated contradictorily. Higuchi et al. [42] showed that the use of pure oxygen allows one to increase the content of $\mathrm{Cr}^{4+}$ centers. According to [44], an increase in the oxygen concentration in the growth atmosphere from 20 to $100 \%$ almost does not change the fraction of $\mathrm{Cr}^{4+}$ ions in the total chromium content. Our estimates obtained for the absolute content of $\mathrm{Cr}^{4+}$ ions from the experimental data taken from [44] indicate that, for the same initial chromium concentration in the melt, the absolute concentration of $\mathrm{Cr}^{4+}$ ions in the crystals grown at oxygen content of $20 \%$ can be even higher $\left(2.5 \times 10^{-3} \mathrm{wt} \%\right)$ than that in the crystals prepared in the pure oxygen atmosphere $\left(9 \times 10^{-4} \mathrm{wt} \%\right)$ (see $[45])$.

We investigated the influence of redox conditions on the content of $\mathrm{Cr}^{4+}, \mathrm{Cr}^{3+}$ and $\mathrm{Cr}^{2+}$ centers in the crystal as well as on the incorporation of total chromium into the crystal during the growth. The series of crystals was grown with different redox conditions $\left(10 \leq P_{\mathrm{O}_{2}} \leq\right.$ $12 \mathrm{kPa}$ ) and with fixed concentration of chromium in the melt $(0.13 \pm 0.2 \mathrm{wt} \%)$ for study of influence of $P_{\mathrm{O}_{2}}$.

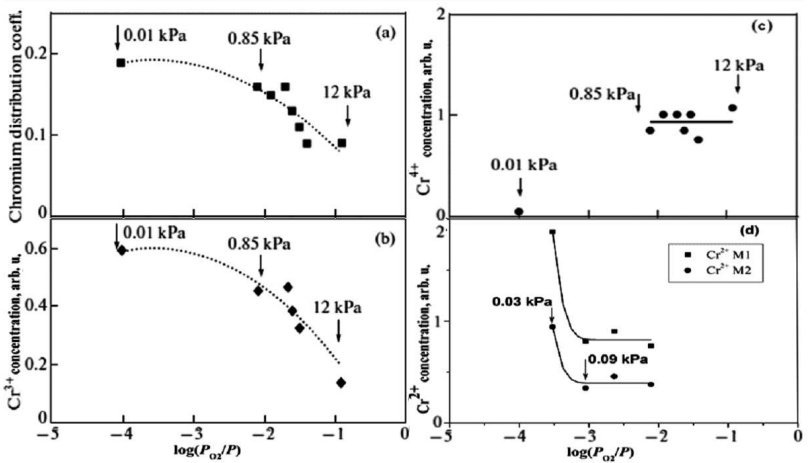

Fig. 3. Dependences of the chromium distribution coefficient between the crystal and the melt of forsterite (a), the content of trivalent chromium (b), tetravalent chromium (c) and divalent chromium (d) in the forsterite crystals on the oxygen partial pressure in the growth atmosphere. Numbers near the arrows indicate the oxygen partial pressures.

Figure 3a shows the dependence of the chromium distribution coefficient between the crystal and the melt of forsterite upon the oxygen partial pressure in the growth atmosphere. This dependence reflects the behavior of all chromium forms with different valences at crystallization from the melt. It should be emphasized that point in 
Fig. 3a, corresponding to $P_{\mathrm{O}_{2}}=0.01 \mathrm{kPa}$, represents the average value of $K_{\mathrm{Cr}}$ for six samples prepared under these redox conditions. It can be seen from this figure that the chromium distribution coefficient decreases by a factor of $\approx 2$ with an increase in $P_{\mathrm{O}_{2}}$ in the oxygen partial pressure range under investigation.

The dependence of the concentration of $\mathrm{Cr}^{3+}$ centers on the oxygen partial pressure is plotted in Fig. 3b. The concentration of $\mathrm{Cr}^{3+}$ centers was evaluated [37] from the intensity of the spectral absorption band with a maximum at $460 \mathrm{~nm}$ (polarization $E \| b$ ), which is associated with these centers. It can be seen from Fig. $3 \mathrm{~b}$ that the content of $\mathrm{Cr}^{3+}$ centers decreases with an increase of the oxygen partial pressure in the particular range and nicely correlates with a variation in the chromium distribution coefficient. The concentration of $\mathrm{Cr}^{3+}$ ions decreases by a factor of $\approx 3$ over the entire range of oxygen partial pressures; in this case, the main changes $(\approx 2.5$ times $)$ correspond to the oxygen partial pressure range $0.85-$ $12.00 \mathrm{kPa}$.

The $\mathrm{Cr}^{4+}$ ions behave in a different manner. The dependence of the concentration of $\mathrm{Cr}^{4+}$ centers on the oxygen partial pressure is shown in Fig. 3c. The concentration of $\mathrm{Cr}^{4+}$ centers in forsterite crystals was evaluated [37] from the intensity of the absorption band at $1085 \mathrm{~nm}$ (polarization $E \| b$ ), which is associated with these centers. The data at $P_{\mathrm{O}_{2}}=0.01 \mathrm{kPa}$ were averaged for seven crystals grown under these conditions. It can be seen from Fig. 3c that in the range of low oxygen partial pressures $(0.01 \mathrm{kPa})$ the concentration of $\mathrm{Cr}^{4+}$ centers is relatively low. As the oxygen partial pressure increases to $0.85 \mathrm{kPa}$, the concentration of $\mathrm{Cr}^{4+}$ centers increases by a factor of $\approx 10$. A further increase in the oxygen partial pressure in the growth atmosphere does not lead to changes in the concentration of $\mathrm{Cr}^{4+}$ ions that exceed the spread in the experimental data.

The relative concentration of $\mathrm{Cr}^{4+}$ ions in the range of variations in the oxygen partial pressure in growth atmosphere from 0.03 to $0.78 \mathrm{kPa}$ was determined from the EPR spectra measured in the X band [39]. The results obtained in this study demonstrate that the jump in the $\mathrm{Cr}^{4+}$ concentration occurs in a considerably narrower range than $0.01<P_{\mathrm{O}_{2}}<0.85 \mathrm{kPa}$ and is completed before the oxygen partial pressure reaches $0.09 \mathrm{kPa}$.

The relative concentration of $\mathrm{Cr}^{2+}$ ions was determined from the EPR spectra measured on a high-frequency tunable EPR spectrometer in the frequency range from 205 to $245 \mathrm{GHz}$ at temperature $4.2 \mathrm{~K}$ [39]. The dependences of the relative concentration of divalent chromium ions in the samples on the partial pressure of oxygen in the growth atmosphere are shown in Fig. 3d. Two transitions are observed for the $\mathrm{Cr}^{2+}(\mathrm{M} 1)$ impurity centers, and the relative concentration of these centers in the samples is determined by the averaging over the integrated intensities of these two transitions with corrections made for their reduced probabilities. It can be seen that, when the partial pressure of oxygen changes in the range from 0.03 to $0.09 \mathrm{kPa}$, the concentration of the
$\mathrm{Cr}^{2+}$ ions dramatically decreases, after which its value reaches saturation and is stabilized.

These results demonstrate that the presence of small amounts of oxygen in the atmosphere during the growth of forsterite single crystals doped with chromium significantly affects the concentration of divalent and tetravalent chromium ions. Concentration of $\mathrm{Cr}^{4+}$ ions at $P_{\mathrm{O}_{2}}>0.09 \mathrm{kPa}$ is stabilized and does not grow anymore with increase of oxygen partial pressure. Nevertheless, the fraction of these ions in the total chromium content considerably increases because of the concentration of $\mathrm{Cr}^{2+}$ and $\mathrm{Cr}^{3+}$ ions decrease with an increase in $P_{\mathrm{O}_{2}}$. It has to be pointed out that the last process is accompanied with simultaneous reduction of $K_{\mathrm{Cr}}$ (Fig. 3a).

The valence state of chromium impurities in the forsterite melt is not known. Ions $\mathrm{Cr}^{2+}, \mathrm{Cr}^{3+}$, and $\mathrm{Cr}^{6+}$ were revealed in a number of silicate melts [46]. Presence of tetravalent chromium in the material is not typical for silicate melts. It seems likely that the overcoming of some barrier with respect to the oxygen concentration in the forsterite matrix is a key factor responsible for $\mathrm{Cr}^{4+}$ appearance in the crystals. It can be assumed that the formation of $\mathrm{Cr}^{4+}$ ions in forsterite crystals is a result of the oxidation of more reduced species. In our recent work [37], the mechanisms of formation of $\mathrm{Cr}^{4+}$ centers in forsterite crystals are discussed in the context of chemistry of defects. A model has been proposed according to which the intrinsic defects, formed under conditions of a relative excess of oxygen compared to stoichiometry (silicon vacancies and holes), results in "self-oxidation" of a part of $\mathrm{Cr}^{3+}$, i.e. change of its valence to $\mathrm{Cr}^{4+}$ with simultaneous transition from octahedral sites to the tetrahedral ones [37]. It is quite probable that divalent chromium is a source providing the formation of tetravalent chromium ions (Fig. 3c and d). Possibly that the oxidation of $\mathrm{Cr}^{2+}$ ions occurs in two stages: first, to the trivalent state and, then, to the tetravalent state.

The experimental data indicate that, in the crystals prepared at low oxygen partial pressures, the number of $\mathrm{Cr}^{4+}$ centers is small. The drastic increase in the concentration of $\mathrm{Cr}^{4+}$ centers is observed in the crystals grown at oxygen partial pressures in the range from 0.01 to $0.09 \mathrm{kPa}$. We can assume that this range involves the oxygen partial pressure corresponding to the exact cation-anion stoichiometric ratio. A further increase in the oxygen partial pressure in the crystal growth atmosphere above $0.09 \mathrm{kPa}$ does not lead to noticeable changes in the concentration of $\mathrm{Cr}^{4+}$ centers. This can be associated with the fact that a substantial excess of oxygen as compared to the stoichiometric composition cannot be produced in the forsterite crystals due to the necessity to form energetically unfavorable defects in the crystals, such as silicon vacancies. The oxygen capacity of the forsterite structure rapidly reaches saturation and does not increase with a further increase in the oxygen partial pressure. In this respect, we can believe that $\mathrm{Cr}^{4+}$ centers could play as indicator that determines the oxygen stoichiometry of the forsterite. 


\subsection{Mutual influence of dopants}

The additional admixtures are a powerful factor changing the properties of chromium-forsterite. The chromium solubility in forsterite depends upon the addition of impurities that introduce an excess positive charge (for example, for scandium) or an excess negative charge (for example, for lithium) substituting the magnesium ions into the matrix. The influence of these impurities takes place in the concentration range where they make a dominant contribution to the electroneutrality condition [47]. Apart from the relation through the electroneutrality condition, the interaction of impurities occurs as a result of the formation of associates between atoms of different types or impurity ions and intrinsic defects of the crystal.

For detailed investigation of influence of co-dopants with different charge on chromium-forsterite two series of crystals with varying contents of scandium and lithium, namely, the "scandium" and "lithium" series were grown. In the scandium series of crystals, the initial chromium content in the melt was equal to $0.25 \mathrm{wt} \%$, and the scandium content was varied in the range from 0.07 to $2.17 \mathrm{wt} \%$. The crystallization was performed at an oxygen partial pressure of $\approx 2.3 \mathrm{kPa}$, which is favorable for tetravalent chromium ions.

In the lithium series of crystals, the initial chromium content in the melt was equal to approximately $0.06 \mathrm{wt} \%$, and the lithium content was varied in the range from 0.01 to $0.42 \mathrm{wt} \%$. Since it was assumed that lithium could increase the concentration of trivalent chromium ions, the crystals of this series were grown under the conditions favorable for trivalent chromium formation at an oxygen partial pressure of $10 \mathrm{~Pa}$.

Admixtures distinctly affect chromium insertion into the crystal. Figure 4 shows the change in the chromium distribution coefficient in forsterite in the case of simultaneous doping with scandium (Fig. 4a) and lithium (Fig. 4b). The initial values of $K_{\mathrm{Cr}}$ in the plots for crystals without additional impurities are different because of the dependence of $K_{\mathrm{Cr}}$ on $P_{\mathrm{O}_{2}}$. Crystals of both $\mathrm{Mg}_{2} \mathrm{SiO}_{4}$ :Cr:Sc and $\mathrm{Mg}_{2} \mathrm{SiO}_{4}$ :Cr:Li exhibit drastic changes in $K_{\mathrm{Cr}}$ upon doping with small amounts of the additional impurity. In this case, scandium decreases the chromium solubility, whereas lithium increases it. At scandium concentration of $0.14 \mathrm{wt} \%$, the chromium distribution coefficient decreases by a factor of three compared to the value of $K_{\mathrm{Cr}}$ in the absence of scandium and then remains unchanged. As the lithium content $C_{\mathrm{L}}(\mathrm{Li})$ increases to $0.04 \mathrm{wt} \%$, the coefficient of chromium distribution between the crystal and the melt increases by a factor of 1.5 compared to the initial value of $K_{\mathrm{Cr}}$. With a further increase in the lithium content above $0.04 \mathrm{wt} \%$, the coefficient of chromium distribution between the crystal and the melt remains unchanged.

The admixtures considerably influence on structural localization and charge state of chromium in forsterite, they change the mechanism of charge compensation. The additional admixtures can result in formation of specific chromium cluster centers that substantially change
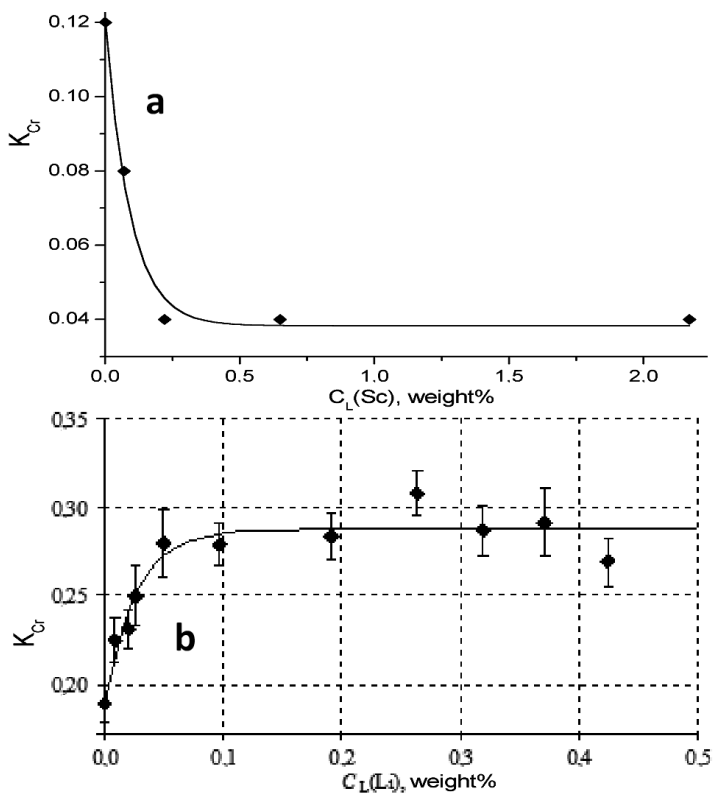

Fig. 4. Dependences of the chromium distribution coefficient of forsterite on the concentrations of scandium (a) and lithium (b) impurities additionally introduced into the melt.

the spectral-luminescent properties of crystals. Study by electron paramagnetic resonance spectroscopy shows the processes occurring during the simultaneous doping of $\mathrm{Mg}_{2} \mathrm{SiO}_{4}$ : $\mathrm{Cr}$ crystals with other impurities more in detail. EPR data $[35,48]$ supported by optical spectroscopy investigations [35, 48, 49] has revealed that co-doping by $\mathrm{Sc}^{3+}$ and $\mathrm{Li}^{+}$starting from their trace contents leads to considerable transformation of chromium centers.

In crystals grown without co-doping, approximately half of the trivalent chromium ions are associated with magnesium vacancies. The addition of lithium leads to the destruction of these associates, an increase in the concentration of individual $\mathrm{Cr}^{3+}$ centers, and the formation of lithium associates with trivalent chromium ions. The conditions for the formation of associates of trivalent chromium ions with lithium ions are optimal when the crystal contains approximately identical amounts of $\mathrm{Cr}^{3+}$ and $\mathrm{Li}^{+}$ions. Doping with lithium increases the concentration of $\mathrm{Cr}^{3+}$ ions and, thus, decreases the fraction of $\mathrm{Cr}^{2+}$ and $\mathrm{Cr}^{4+}$ ions in the total content of chromium centers.

In the case of scandium co-doping there were demonstrated $[38,48]$ a decrease in the concentration of the individual centers $\mathrm{Cr}_{\mathrm{M} 1}^{\bullet}$ and $\mathrm{Cr}_{\mathrm{M} 2}^{\bullet}$, associates of the $\mathrm{Cr}_{\mathrm{M} 1}^{\bullet}$ centers with magnesium vacancies, and the $\mathrm{Cr}_{\mathrm{Si}}^{\times}$centers, which is accompanied by the simultaneous formation of mixed associates of chromium and scandium with magnesium vacancies of the type $\left(\mathrm{Cr}_{\mathrm{M} 1} \mathrm{v}_{\mathrm{M} 2} \mathrm{Sc}_{\mathrm{M} 1}\right)^{\times}$.

It should be noted that, in the range of low scandium concentrations, a drastic decrease is observed for both the trivalent and tetravalent chromium contents. A decrease in the concentration of "uncharged" $\mathrm{Cr}_{\mathrm{Si}}^{\times}$ions upon doping with scandium can be explained in the frame- 
work of the model describing the formation of tetravalent chromium ions in the process of self-oxidation of the $\mathrm{Cr}_{\mathrm{Mg}}^{\bullet}$ ions [37].

Although the initial chromium content in the melt of the scandium series was substantially higher than that of the lithium series ( 0.25 and $0.06 \mathrm{wt} \%$, respectively), the change in the behavior of the concentration dependences characterizing the chromium centers, in both cases, is observed in the range of microconcentrations of the additionally introduced impurity of the order of $10^{-5}$ atomic fractions. The observed phenomenon is explained by the interaction of impurities with intrinsic defects of the crystal [38]. The solubility of impurity atoms in the charged form abruptly changes at the point where their concentration becomes higher than the concentration of predominant intrinsic defects.

The optically inactive lithium impurity substantially affects the spectral and luminescence properties of the $\mathrm{Mg}_{2} \mathrm{SiO}_{4}$ :Cr crystals. The broad band luminescence of trivalent chromium ions in forsterite crystals exhibits a maximum at $\lambda=850-900 \mathrm{~nm}$ depending on the polarization [50]. Upon additional doping with lithium, this band rapidly weakens and, when the lithium content reaches $C_{\mathrm{L}}(\mathrm{Li})=(3-5) \times 10^{-2}$ wt\%, completely disappears; therefore, it can be identified with chromiumvacancy associates [49]. After the disappearance of the luminescence with a maximum in the range 850-900 nm, there arise bands attributed to the $\left(\mathrm{Cr}_{\mathrm{Mg}}^{\bullet} \mathrm{Li}_{\mathrm{Mg}}^{\prime}\right)^{\times}$centers with maxima at $750 \mathrm{~nm}(\boldsymbol{E} \| \boldsymbol{a})$ and $950 \mathrm{~nm}(\boldsymbol{E} \| \boldsymbol{c})$, whose intensity increases with an increase in the lithium content $C_{\mathrm{L}}(\mathrm{Li})$. Based on obtained results the new laser material has been created: forsterite crystals with active centers $\mathrm{Cr}^{3+}(\mathrm{M} 2)-\mathrm{Li}^{+}(\mathrm{M} 1)$ emitting in a new spectral region around one micron [30].

\section{Scheelite-like double tungstates and molybdates}

Double tungstate (DW) and double molybdate (DMo) crystals with the generic composition of $\mathrm{M}^{+} \mathrm{T}^{3+}\left(\mathrm{XO}_{4}\right)_{2}$ (where $\mathrm{M}=\mathrm{Li}^{+}, \mathrm{Na}^{+}$, or $\mathrm{K}^{+} ; \mathrm{T}=\mathrm{Ln}^{3+}, \mathrm{Y}^{3+}$, or $\mathrm{Bi}^{3+}$; and $\mathrm{X}=\mathrm{W}^{6+}$ or $\mathrm{Mo}^{6+}$ ), in short MTX, are the derivatives of scheelite $\mathrm{CaWO}_{4}$, where two $\mathrm{Ca}^{2+}$ ions are replaced by a $\mathrm{M}^{+} \mathrm{T}^{3+}$ ion couple. These crystals drew attention due to their attractive spectroscopic properties and broad isomorphic capacity giving the possibility of incorporating large amounts of lanthanide ions.

We concentrate on the sodium-content group of DW and DMo crystals, which have scheelite-like structure; they are comparable in luminescent properties with well-known potassium-containing monoclinic tungstates like $\mathrm{KGd}\left(\mathrm{WO}_{4}\right)_{2}$, but have the important advantage: they undergo no polymorphic transformations, and, accordingly, can readily be grown directly from the melt, in particular, by the Czochralski process, except a few compounds with incongruent melting, such as NaTmW, $\mathrm{NaYbW}$, and NaLuW [51].

The raising interest to the double tungstates and molybdates with the scheelite-type structure as active laser media have led to the significant number of papers published in recent years and devoted to the study of spectral-luminescent and lasing properties of these crystals (see, for review [51]).

In the scheelite $\left(\mathrm{CaWO}_{4}\right)$ structure (spatial group $I 41 / a), \mathrm{Ca}^{2+}$ located in a severely distorted dodecahedral oxygen coordination, with two sets of bond distances: $\mathrm{CN}=4+4$. Each $\mathrm{CaO}_{8}$ polyhedron shares the edges with four analogous dodecahedra. W or Mo ions occupy slightly distorted tetrahedral sites. The substitution of $\mathrm{Ca}^{2+}$ for $\mathrm{Na}^{+}$and $\mathrm{Ln}^{3+}$ cations in $\mathrm{NaLn}\left(\mathrm{TO}_{4}\right)_{2}$ gives the first grade of structural disorder. $\mathrm{Na}^{+}$and $\mathrm{Ln}^{3+}$ ions lie between the tetrahedra along the fourth-order crystallographic axis and either almost strictly statistically or quasi-statistically distributed over the former $\mathrm{Ca}^{2+}$ crystallographic sites, producing rather smooth inhomogeneously broadened absorption and luminescence bands of rare-earth activators. Table II demonstrates the considerable broadening of $\mathrm{Yb}^{3+}$ fluorescence narrow band in double tungstates compared to scheelite $\mathrm{CaWO}_{4}$ [52]. The cation distribution on the dodecahedral (calcium) sites in the $\mathrm{NaLn}\left(\mathrm{TO}_{4}\right)_{2}$ phases may be partially or fully disordered depending on the composition.

TABLE II

Half-widths of ytterbium fluorescence lines in scheelite tungstates.

\begin{tabular}{c|c|c|c}
\hline \hline Crystal & $\begin{array}{c}\mathrm{C}_{\mathrm{Yb}} \times 10^{-20} \\
{\left[\mathrm{~cm}^{-3}\right]}\end{array}$ & $\begin{array}{c}\text { The maximum } \\
\text { of the narrow } \\
\text { band [nm] }\end{array}$ & $\begin{array}{c}\text { Half-width } \\
\text { of the narrow } \\
\text { band [nm] }\end{array}$ \\
\hline $\mathrm{Yb}: \mathrm{CaWO} 4$ & 1.7 & 977.9 & 1.8 \\
$\mathrm{Yb}: \mathrm{NaLa}\left(\mathrm{WO}_{4}\right)_{2}$ & 2.0 & 976.7 & 3.5 \\
$\mathrm{Yb}: \mathrm{NaGd}\left(\mathrm{WO}_{4}\right)_{2}$ & 3.5 & 975.5 & 3.8
\end{tabular}

The second stage of disorder in scheelite structure may be accomplished by additional partial substitution of host rare-earth ions in dodecahedral sites. One example is given in Ref. [53]. The crystals of mixed scheelite-like tungstates $\mathrm{Tm}^{3+}: \mathrm{NaLa}_{x} \mathrm{Gd}_{1-x}\left(\mathrm{WO}_{4}\right)_{2}$ with a variable La-Gd composition occupy an intermediate position between the lanthanum and gadolinium tungstates. Our estimates show that the absorption cross section for the ${ }^{3} \mathrm{H}_{6}-{ }^{3} \mathrm{H}_{4}$ transition and the stimulated emission cross section for the ${ }^{3} F_{4}-{ }^{3} H_{6}$ transition of $\mathrm{Tm}^{3+}$ ions in mixed scheelite crystals are comparable with the corresponding characteristics for $\mathrm{Tm}^{3+}: \mathrm{NaGd}\left(\mathrm{WO}_{4}\right)_{2}$ and $\mathrm{Tm}^{3+}: \mathrm{NaLa}\left(\mathrm{WO}_{4}\right)_{2}$ crystals [53].

The further disorder of scheelite structure may be obtained by mutual partial substitution between $\mathrm{W}$ and Mo in tetrahedral sites. The realization of this substitution is not so easy as in case of dodecahedral sites due to significantly larger rigidity of tetrahedra compared to other coordination polyhedra in the structure.

DW and DMo crystals were grown from the melt by the Czochralski method from a platinum-rhodium crucible in air with RF heating. The charge for growth was prepared by standard calcining of thoroughly mixed initial chemicals $\mathrm{Na}_{2} \mathrm{CO}_{3}, \mathrm{Ln}_{2} \mathrm{O}_{3}$ and $\mathrm{WO}_{3}\left(\mathrm{MoO}_{3}\right)$ of extra-pure grade, taken in the ratios, which provide stoichiometric 
composition of the melt. The activator was introduced directly into the initial charge in the form of trivalent oxide.

In some papers (see, for instance, Ref. [54]) two-step solid-phase synthesis of charge for the Czochralski growth of scheelite-like double tungstate single crystals was used. (Firstly the mixture was slowly heated to $750{ }^{\circ} \mathrm{C}$ and held at this temperature for $18 \mathrm{~h}$. In the second step this powder was cooled down to room temperature and then heated again up to $850^{\circ} \mathrm{C}$ and held at this temperature for $24 \mathrm{~h}$ ). In our experiments we have not observed pronounced negative influence of simplification of the technology of charge synthesis onto the quality of grown crystals. In fact, even in the case of incompleteness of synthesis the compound during solid-phase reaction, this synthesis will be very quickly completed immediately after melting of the charge, before seeding.

The pulling rate at different growth stages was varied to ensure an actual velocity of the crystallization front (taking into account the gradual decrease in the melt level in the crucible), irrespective of the growth stage (growth of the cone or the cylindrical part), of $1.2 \mathrm{~mm} / \mathrm{h}$ for heavily doped samples (more than 1 at.\% of dopant) and $2-2.5 \mathrm{~mm} / \mathrm{h}$ for lightly doped sample. The rotation rate was $10 \mathrm{rpm}$. The average diameter of the crystals grown was $15-18 \mathrm{~mm}$ and their length ranged from 20 to $40 \mathrm{~mm}$.

The actual concentrations of rare-earth dopants in the grown crystals were measured at cylindrical parts of boules by microprobe analysis at the analyzer Camebax SX-50. The evaluated values of distribution coefficients in the studied crystals are listed in Table III.

TABLE III

Distribution coefficients of some rare-earth dopants in double tungstates and molybdates.

\begin{tabular}{c|c|c|c|c|c}
\hline \hline Crystal $\backslash$ Dopant & Yb & Ho & Tm & Er & Ce \\
\hline $\mathrm{NaGd}\left(\mathrm{WO}_{4}\right)_{2}$ & 0.8 & - & 0.7 & 0.7 & - \\
$\mathrm{NaLa}\left(\mathrm{MoO}_{4}\right)_{2}$ & 0.5 & 0.5 & 0.5 & 0.4 & 1 \\
$\mathrm{NaGd}\left(\mathrm{MoO}_{4}\right)_{2}$ & 0.75 & - & - & - & - \\
$\mathrm{NaLa}\left(\mathrm{WO}_{4}\right)_{2}$ & 0.5 & - & - & - & -
\end{tabular}

Although the crystals were grown in air, they showed additional optical absorption due to the oxygen nonstoichiometry. The as-grown crystals were annealed in air to remove stresses and eliminate oxygen nonstoichiometry. The annealing was performed for $48 \mathrm{~h}$. In the first stage, the annealing temperatures about $100 \mathrm{~K}$ below the melting temperature of the crystals were used. However, such annealing leads to significant degradation of the optical quality of crystals (the occurrence of turbidity). Then the annealing temperature was reduced to $700^{\circ} \mathrm{C}$. Annealing of the crystals under these conditions did not lead to the occurrence of turbidity.

During the growth process a slight evaporation of $\mathrm{WO}_{3}$ $\left(\mathrm{MoO}_{3}\right)$ occurs, that leads to gradual shift of the melt composition out from stoichiometry. The crystalline boules, grown from strictly stoichiometric melts, have stronger tendency to crack, and their surface is considerably etched, especially at the end parts of the boule. In order to avoid this problem, we used the melts with slight $(0.5-1 \%)$ excess of $\mathrm{WO}_{3}\left(\mathrm{MoO}_{3}\right)$. In this case, grown crystals have mirror-like smooth surface from beginning to the end parts of boule [55]. Other authors are using either the same way of compensation the $\mathrm{WO}_{3}$ evaporation during the growth (see, for instance, [56]), or add a slight amount of $\mathrm{Na}_{2} \mathrm{~W}_{2} \mathrm{O}_{7}$ (see [57], and later papers of these authors).

The serious problem in the growth of crystals of this type is their tendency to cracking predominantly in the (001) cleavage plane (perpendicularly to the optical axis). Cracking may occur during both the growth process and upon cooling of as-grown crystal to room temperature. This phenomenon is caused by thermoelastic stresses developing under the influence of the temperature gradient and relatively low mechanical durability of scheelite-like crystals. For the (001) plane, the stresses necessary for crack formation are much lower due to the significant anisotropy of the coefficients of thermal expansion. The thermal expansion coefficient along $\mathrm{C}$-axis in scheelitelike DT and DM crystal is approximately twice larger than that perpendicularly to C-axis [58]. In order to prevent such a cracking we used the growth directions parallel to the cleavage plane (001). In view of the above considerations, crystals were grown using a configuration of heat shields providing the minimal possible radial temperature gradients, while conserving an axial temperature gradient sufficient to ensure stable crystal growth and eliminate problems related to constitutional supercooling of the melt.

The significant drawback of ceramic heat shields configuration is the presence of a through hole in the radial direction, which served as a watching window. This inspection hole makes a significant distortion in the shape of the temperature field, making it asymmetrical in the radial direction. That was one of the major causes of the cracks in the crystals.

Introduction of entire quartz cylinder inside the ceramic heat-shields appear to be unsuccessful since such a close location to the melt leads to quite rapid loss of transparency of the quartz due to the condensation of vapor products of the melt on window surface. Displacement of quartz cylinder away from the melt to the outer layer of heat-shields or use a simple quartz plate covering the watching window allowed strongly reducing of the heat removal through it and reducing significantly the cracking, keeping at the same time the acceptable transparency of the window throughout the growth process.

Modification of the heat-shields allowed us to avoid the problem of cracking of crystals on the stage of crystal growth. However, the crystals continued to crack at the stage of after-growth cooling down to room temperature. It was observed that the cracking occurs predominantly in the final stages of cooling at temperatures below $600{ }^{\circ} \mathrm{C}$. Therefore, we have made additional improve- 
ments to the configuration of heat shields, namely, introduced the resistance heating furnace with a platinum wire coiled around the inner heat shield. The furnace was operated by a programmable thermo-controller. During the crystal growth process the temperature was maintained at $700{ }^{\circ} \mathrm{C}$. At the end of growth, after disconnection from the melt crystal rised to the resistive furnace. RF heating was switched off and the furnace was programmed to reduce the temperature at $10-20^{\circ} \mathrm{C}$ per hour. This improvement made it possible, first, to substantially mitigate the temperature gradients above the crucible, and secondly, to reduce the cooling rate. As a result, the problem of cracking of crystals was practically resolved. Moreover, additional annealing of crystals in a muffle furnace after the introduction of this procedure is generally not required.

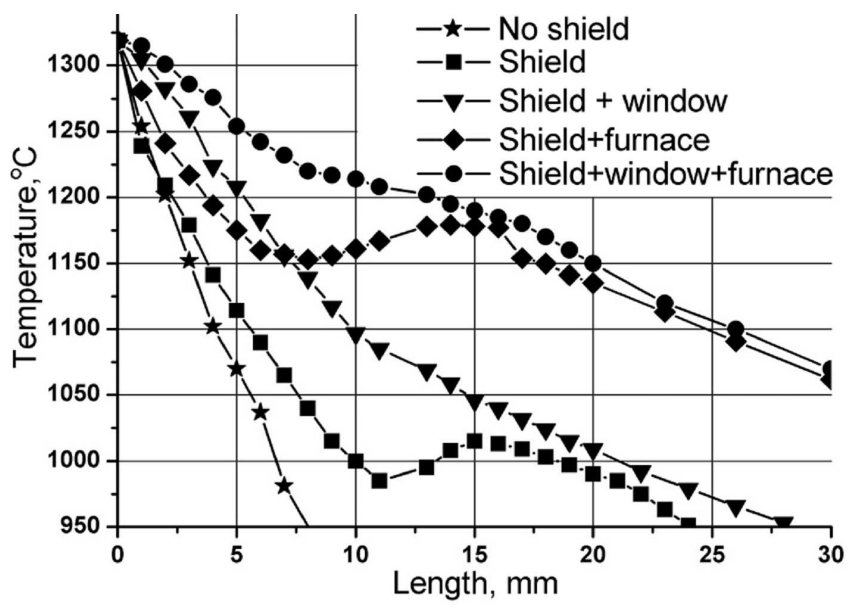

Fig. 5. The temperature distribution above the NGW:Tm melt surface.

Figure 5 shows the temperature distribution above the crucible at different combinations of designed thermal shields. The temperature was measured using a thermocouple attached to the seed holder, in the absence of a growing crystal. Measurements were carried out under the following conditions:

A) without heat shields - the curve "No shield";

B) double-layer heat shield with open inspection hole the curve "Shield";

C) double-layer heat shield, an open inspection hole and a resistance furnace - the curve "Shield + furnace";

D) double-layer heat shield, inspection hole is covered with a quartz plate - the curve "Shield + window";

E) double-layer heat shield, inspection hole is covered with a quartz plate and resistance furnace - the curve "Shield + window + furnace".

One can see that the changes made in the design of heat-shields, have made nearly uniform axial temperature gradient $(\approx 9 \mathrm{~K} / \mathrm{mm})$ along the crystal growth axis and greatly reduced the asymmetry of the thermal field caused by a viewing window.
The temperature of after-growth annealing in the growth chamber was not higher than $400-500^{\circ} \mathrm{C}$ below the melting point. At higher annealing temperatures the crystals become opaque and useless as laser materials. It was shown in Ref. [59] that crystals, which became opaque by high-temperature annealing, contained higher density of structural defects, such as stacking faults, dislocations, and point defect complexes.

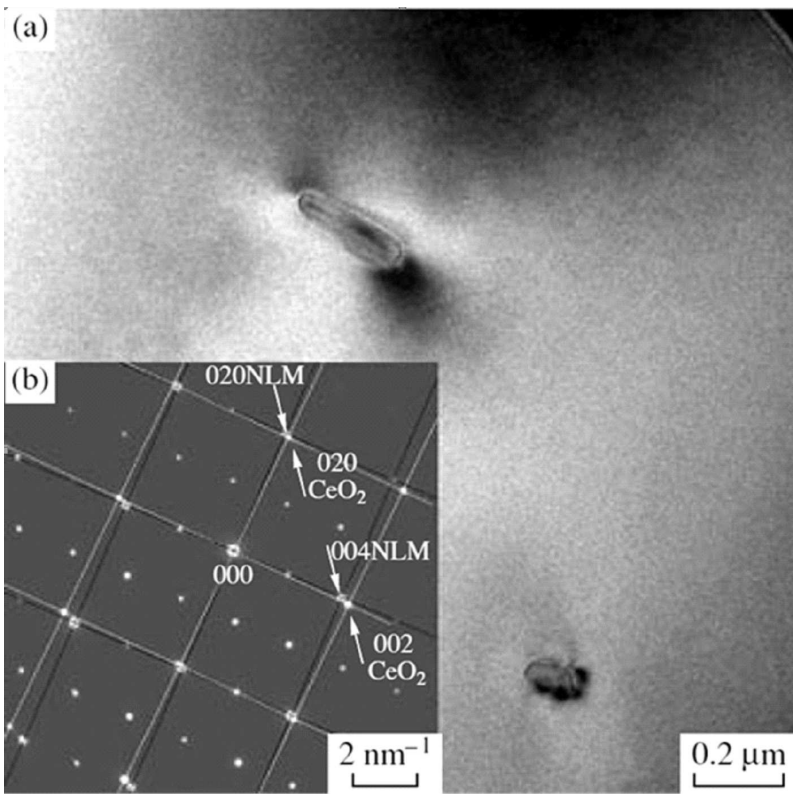

Fig. 6. TEM image (a) and electron diffraction pattern (b) of the annealed crystal NLM:Ce,Er, containing $\mathrm{CeO}_{2}$ crystallites.

Microstructural analysis of the unannealed (transparent) and annealed (opaque) crystals $\mathrm{NaLa}\left(\mathrm{MoO}_{4}\right)_{2}$, doped by Er, Ce (NLM:Er,Ce) performed in Ref. [60] by electron microscopy, transmission electron diffraction, and X-ray microanalysis showed that the crystals contained $\mathrm{CeO}_{2}$ precipitates. In the unannealed crystal, the particle size of ceria were less than $0.1 \mu \mathrm{m}$, which does not affect the laser quality of the samples, whereas the annealed crystal contains well-faceted ceria crystallites up to $0.3 \mu \mathrm{m}$ in size, which leads to the opaque and scattering. Moreover, the ceria particles in the unannealed crystal have a tendency to align in specific directions. The angle between such directions indicates that precipitation occurs in (001) and (012) or in (011) planes. Annealing increases the precipitate size, but the ceria particles remain aligned in certain directions. The transmission electron microscope demonstrated that, in the unannealed crystal, precipitation occurs at dislocations (Fig. 6).

The choice of growth ambient atmosphere is also very important factor, especially in the case of Ce-doped crystals. On the one hand, the oxidation potential of growth atmosphere should not be too high, because otherwise it will be rather difficult for $\mathrm{Ce}^{4+}$ ions (introduced into the charge as $\mathrm{CeO}_{2}$ ) to alter their oxidation state for $3+$. On 
the other hand, the annealing of scheelite-like molybdates in the ambient with very low oxygen partial pressure (in particular, vacuum [61]) can lead to the formation of the color centers.

In addition to the spectral lines caused by the presence of rare earth ions, many of the grown crystals, especially molybdates, demonstrate the additional optical absorption [62]. This absorption band has the shape and the range of wavelengths very similar to that of $\mathrm{NaBi}\left(\mathrm{MoO}_{4}\right)_{2}$ crystals, annealed in vacuum [61]. When additional absorption is expanding to the fluorescence range of rare earth activators (Fig. 7), it can negatively affect the lasing parameters of crystals.

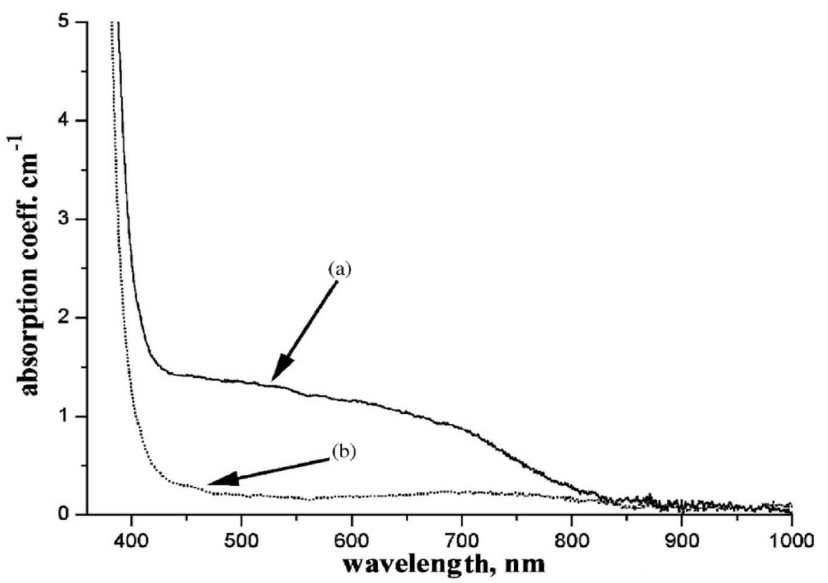

Fig. 7. The absorption spectra of black-coloured $\mathrm{NaLa}\left(\mathrm{MoO}_{4}\right)_{2}$ crystal grown in neutral atmosphere (a), and the crystal, annealed in air (b).

To study the causes of this phenomenon, we carried out the experiments to measure the electrical conductivity of the crystals at different temperatures [62]. Electrical conductivity measurements carried out before and after annealing on a NGM:Tm crystal, which had the deepest and most stable black color of the samples studied, showed that the values measured at $20^{\circ} \mathrm{C}$ were below the threshold of the determination. For the non-annealed sample, nonzero conductivity was observed starting with $240^{\circ} \mathrm{C}$, and for the annealed sample, starting with $400^{\circ} \mathrm{C}$, and starting with these values, temperature dependent electrical conductivity was close to the monoexponent law in both samples. The processing of the experimental dependence of the electrical conductivity of the colored samples showed that the charge carriers in our studied samples are electrons. Due to the high degree of localization of electrons on oxygen vacancies, the electrical conductivity of the samples at room temperature demonstrates very low values. In non-annealed samples, broad, strong and structureless absorption bands are observed. Upon annealing, the concentration of oxygen vacancies (and, accordingly, the concentration of potentially free electrons) in molybdates crystal considerably decreases; as a result, conductivity and optical absorption intensity are strongly reduced.
The optical absorption of black and dark-lilac non-annealed samples in the range $400-1500 \mathrm{~nm}$ is well fitted by the sum of two elementary Gaussians, which can correspond to either two different electron transitions in one optical center or to transitions of two different types of optical centers. It was shown [62] that in non-annealed samples there are at least two interrelated types of optical centers based on intrinsic defects; one is an oxygen vacancy based center and the other may be $\mathrm{Mo}^{5+}$ ion in $\mathrm{Mo}^{6+}$ position. Such a defect, along with free electrons, can also serve as a charge compensator for oxygen vacancies. An oxygen deficient crystal growth atmosphere can fairly enhance partial reduction of molybdenum.

\section{Acknowledgments}

This study has been partially supported by Russian Fund for Basic Research (grants Nos. 11-02-01233 and 12-02-01343).

\section{References}

[1] J. Czochralski, Z. Phys. Chem. 92, 219 (1918).

[2] G. Müller, Cryst. Res. Technol. 42, 1150 (2007).

[3] E.V. Zharikov, J. Cryst. Growth 360, 146 (2012).

[4] K. Nassau, L.G. Van Uitert, J. Appl. Phys. 31, 1508 (1960).

[5] Selected Papers on Laser Crystal Growth, Ed. R. Uhrin, SPIE Milestone Series, Vol. MS 164, Bellingham, Washington 2000.

[6] E.V. Zharikov, Proc. SPIE 1839, 46 (1992).

[7] E.V. Zharikov, G.M. Kuz'micheva, S.G. Novikov, in: Growth of Crystals, Vol. 21, Eds. E.I. Givargizov, A.M. Melnikova, Kluwer Acad., New York 2002, p. 155.

[8] E.V. Zharikov, V.A. Smirnov, in: Wide-Gap Luminescent Materials: Theory and Applications, Ed. S.R. Rotman, Kluwer Acad. Publ., Boston 1997, p. 13.

[9] E.V. Zharikov, L.V. Prihod'ko, N.R. Storozhev, J. Cryst. Growth 99, 910 (1990).

[10] E.V. Zharikov, in: Crystal Growth Technology. Semiconductors and Dielectrics, Eds. P. Capper, P. Rudolph, Wiley-VCH, Weinheim 2010, p. 41.

[11] www.northropgrumman.com/BusinessVentures/ SYNOPTICS/Products/LaserCrystals/Pages/ default.aspx .

[12] J.S. Liu, J.J. Liu, Y. Tang, Laser Phys. 18, 1124 (2008).

[13] F. Kallmeyer, M. Dziedzina, X. Wang, H.J. Eichler, C. Czeranowsky, B. Ileri, K. Petermann, G. Huber, Appl. Phys. B 89, 305 (2007).

[14] E.A. Khazanov, A.M. Sergeev, Laser Phys. 17, 1398 (2007).

[15] H. Okada, M. Tanaka, H. Kiriyama, Y. Nakai, Y. Ochi, A. Sugiyama, H. Daido, T. Kimura, T. Yanagitani, H. Yagi, N. Meichin, Opt. Lett. 35 , 3048 (2010).

[16] S. Gupta, S. Kumar, Trends Biomater. Artif. Organs 25, 119 (2011).

[17] S. Shahabi, N. Chiniforush, H. Bahramian, A. Monzavi, A. Baghalian, M.J. Kharazifard, Lasers Med. Sci. 28, 139 (2013). 
[18] A. Ikesue, Y.L. Aung, Nature Photon. 2, 721 (2008).

[19] J. Carreaud, R. Boulesteix, A. Maître, Y. Rabinovitch, A. Brenier, A. Labruyère, V. Couderc, Opt. Mater. 35, 704 (2013).

[20] N.J. Cherepy, J.D. Kuntz, J.J. Roberts, T.A. Hurst, O.B. Drury, R.D. Sanner, T.M. Tillotson, S.A. Payne, Proc. SPIE 7079, 70790X (2008).

[21] J. Ueda, K. Aishima, S. Tanabe, Opt. Mater. (2013).

[22] V.B. Glushkova, E.V. Zharikov, S.Yu. Zinoviev, V.A. Krzhizhanovskaja, V.V. Osiko, P.A. Studenikin, Doklady 295, 907 (1987) (in Russian).

[23] E.V. Zharikov, Cryst. Res. Technol. 24, 745 (1989).

[24] V.A. Efremov, G.M. Kuzmicheva, S.N. Kozlikin, E.V. Zharikov, S.P. Kalitin, V.V. Osiko, J. Inorg. Chem. 32, 2366 (1987) (in Russian).

[25] P.A. Popov, N.N. Sirota, E.V. Zharikov, A.I. Zagumennyi, G.B. Lutts, I.A. Ivanov, Laser Phys. 1, 466 (1991).

[26] T.T. Basiev, E.V. Zharikov, V.V. Osiko, Cryst. Rep. 47, 15 (2002)

[27] E.V. Zharikov, in: OSA Proc. Advanced Solid-State Lasers, Eds. H.P. Jenssen, G. Dube, Vol. 6, OSA, Washington 1991, p. 292.

[28] A.L. Denisov, E.V. Zharikov, S.V. Lavrishchev, N.N. Bakhurova, K.A. Subbotin, I.A. Shcherbakov, Inorg. Mater. 32, 1327 (1996) (in Russian).

[29] V. Petricevic, S.K. Gayen, R.R. Alfano, Appl. Phys. Lett. 53, 2590 (1988).

[30] A.V. Gaister, E.V. Zharikov, V.F. Lebedev, A.S. Podstavkin, S.Yu. Tenyakov, A.V. Shestakov, A.I. Shcherbakov, Quant. Electr. 34, 693 (2004).

[31] G.S. Shakurov, V.F. Tarasov, Appl. Magn. Reson. 21, 597 (2001).

[32] I.D. Ryabov, Phys. Chem. Miner. 38, 177 (2010).

[33] T.F. Veremeichik, E.V. Zharikov, V.B. Dudnikova, A.V. Gaister, N.N. Eremin, V.A. Smirnov, K.A. Soubbotin, V.S. Urusov, I.A. Shcherbakov, Opt. Mater. 19, 319 (2002).

[34] E.V. Zharikov, A.V. Gaister, V.B. Dudnikova, V.S. Urusov, J. Cryst. Growth 275, e871 (2005).

[35] E.V. Zharikov, V.F. Lebedev, V.B. Dudnikova, A.V. Gaister, I.D. Ryabov, in: World of Minerals, Crystals, and Nanostructures, Eds. N.P. Yushkin, V.I. Rakin, Geoprint, Syktyvkar 2008, p. 157 (in Russian).

[36] A.A. Konovalov, V.F. Tarasov, V.B. Dudnikova, E.V. Zharikov, Phys. Solid State 51, 1626 (2009).

[37] V.B. Dudnikova, E.V. Zharikov, V.S. Urusov, Phys. Solid State 52, 1865 (2010).

[38] V.B. Dudnikova, E.V. Zharikov, V.S. Urusov, Phys. Solid State 53, 2227 (2011).

[39] D.A. Akhmetzyanov, V.B. Dudnikova, E.V. Zharikov, E.R. Zhiteitsev, O.N. Zaitseva, A.A. Konovalov, V.F. Tarasov, Phys. Solid State 55, 520 (2013).

[40] P. Peicong, Z. Hongbin, Y. Shenhui, J. Cryst. Growth 121, 141 (1992).

[41] V.B. Dudnikova, V.S. Urusov, Geokhimiya 483, 4 (1992) (in Russian).
[42] M. Higuchi, R.F. Geray, R. Dieckmann, D.G. Park, J.M. Burlitch, D.B. Barber, C.R. Pollock, J. Cryst. Growth 148, 140 (1995).

[43] D.G. Park, J.M. Burlitch, R.F. Geray, R. Dieckmann, D.B. Barber, C.R. Pollock, Chem. Mater. 5, 518 (1993).

[44] J.L. Mass, J.M. Burlitch, S.A. Markgraf, M. Huguchi, R. Dieckmann, D.B. Barber, C.R. Pollock, J. Cryst. Growth 165, 250 (1996).

[45] V.B. Dudnikova, A.V. Gaister, E.V. Zharikov, V.G. Senin, V.S. Urusov, Geokhimiya 519, 5 (2005) (in Russian).

[46] H.D. Schreiber, L.A. Haskin, in: Proc. Seventh Lunar Science Conf., Houston (TX), Vol. 1, Pergamon, New York 1976, Vol. 1, p. 1221.

[47] F.A. Kroeger, The Chemistry of Imperfect Crystals, North-Holland, Amsterdam 1964.

[48] I.D. Ryabov, Phys. Chem. Minerals 39, 725 (2012).

[49] V.F. Lebedev, I.D. Ryabov, A.V. Gaister, A.S. Podstavkin, E.V. Zharikov, A.V. Shestakov, Phys. Solid State 47, 1504 (2005).

[50] V.F. Lebedev, A.V. Gaister, S.Yu. Tenyakov, A.E. Levchenko, E.M. Dianov, E.V. Zharikov, Quant. Elect. 33, 197 (2003).

[51] E.V. Zharikov, C. Zaldo, F. Diaz, MRS Bull. 34, 271 (2009).

[52] K.A. Subbotin, E.V. Zharikov, V.A. Smirnov, Opt. Spectrosc. 92, 601 (2002).

[53] F.A. Bol'shchikov, E.V. Zharikov, N.G. Zakharov, D.A. Lis, P.A. Ryabochkina, K.A. Subbotin, O.L. Antipov, Quant. Electr. 40, 101 (2010).

[54] M.D. Serrano, F. Esteban-Betegón, C. Zaldo, J. Cryst. Growth 275, e819 (2005).

[55] F.A. Bolschikov, G.M. Kuz'micheva, D.A. Lis, Yu.M. Papin, A.V. Popov, P.A. Ryabochkina, V.B. Rybakov, V.G. Senin, V.A. Smirnov, K.A. Subbotin, Yu.K. Voron'ko, V.V. Voronov, E.V. Zharikov, J. Cryst. Growth 311, 4171 (2009).

[56] J. Fan, H. Zhang, J. Wang, Z. Ling, H. Xia, X. Chen, Y. Yu, Q. Lu, M. Jiang, J. Phys. D, Appl. Phys. 39, 1034 (2006)

[57] J.M. Cano-Torres, M.D. Serrano, C. Zaldo, M. Rico, X. Mateos, J. Liu, U. Griebner, V. Petrov, F.J. Valle, M. Galan, G. Viera, J. Opt. Soc. Am. B 23, 2494 (2006).

[58] H. Wang, G. Jia, F. Yang, Y. Wei, Z. You, Y. Wang, J. Li, Z. Zhu, X. Lu, C. Tu, Appl. Phys. B 83, 579 (2006).

[59] E.V. Zharikov, G.M. Kuz'micheva, D.A. Lis, Yu.M. Papin, V.B. Rybakov, B.A. Smirnov, K.A. Subbotin, Inorg. Mater. 39, 151 (2003).

[60] E.I. Suvorova, G.M. Kuz'micheva, A.V. Morozkin, E.V. Zharikov, D.A. Lis, K.A. Subbotin, Inorg. Mater. 43, 287 (2007).

[61] V. Volkov, M. Rico, A. Mendez-Blas, C. Zaldo, J. Phys. Chem. Solids 63, 95 (2002).

[62] G.M. Kuzmicheva, V.B. Rybakov, K.A. Subbotin, E.V. Zharikov, D.A. Lis, O. Zaharko, D.A. Nikolaev, V.G. Senin, Rus. J. Inorg. Chem. 57, 1128 (2012). 